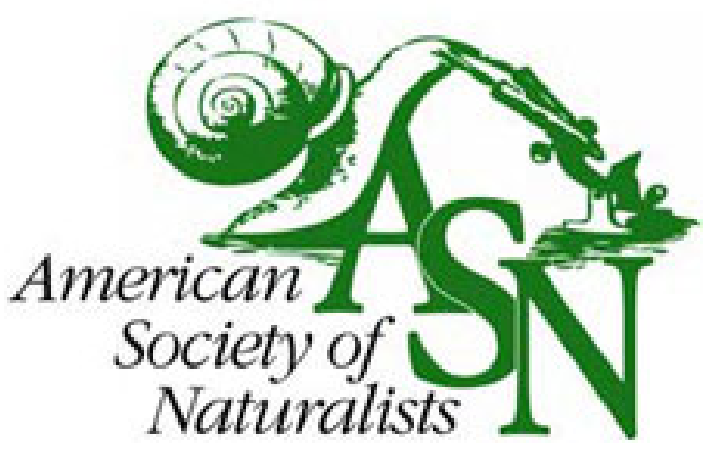

Optimal Habitat Selection in Time-Limited Dispersers

Author(s): S. A. Ward

Reviewed work(s):

Source: The American Naturalist, Vol. 129, No. 4 (Apr., 1987), pp. 568-579

Published by: The University of Chicago Press for The American Society of Naturalists

Stable URL: http://www.jstor.org/stable/2461662

Accessed: 23/02/2012 04:18

Your use of the JSTOR archive indicates your acceptance of the Terms \& Conditions of Use, available at http://www.jstor.org/page/info/about/policies/terms.jsp

JSTOR is a not-for-profit service that helps scholars, researchers, and students discover, use, and build upon a wide range of content in a trusted digital archive. We use information technology and tools to increase productivity and facilitate new forms of scholarship. For more information about JSTOR, please contact support@jstor.org. 


\title{
OPTIMAL HABITAT SELECTION IN TIME-LIMITED DISPERSERS
}

\author{
S. A. WARD* \\ Department of Theoretical Production Ecology, Agricultural University, P.O. Box 430, \\ 6700 AK Wageningen, Netherlands
}

Submitted December 6, 1985; Revised June 12, 1986; Accepted July 21, 1986

The life cycles of a wide variety of organisms include a dispersal phase that precedes reproduction. The main function of this stage is to select an appropriate habitat for reproduction and the development of offspring. Several models of optimal habitat selection have assumed that the optimal behavior results in an "ideal free distribution," in which no individual could increase its fitness by being elsewhere (e.g., Fretwell and Lucas 1970; Fretwell 1972). In species whose dispersal stage is brief or marked by heavy mortality, however, the benefits of rejecting suboptimal habitats may be outweighed by the cost of failing to find a habitat at all.

Models of time-limited habitat selection have been presented by Levins (1968), Levins and MacArthur (1969), Jaenike (1978), and Courtney (1982). Specificity (i.e., rejection of suboptimal habitats) is favored if optimal habitats are abundant, if a long time is available for the search, or if fitness in inferior habitats is low. A related model has been used to explain the high incidence of polyphagy among aphids inhabiting areas of high floral diversity, since this is associated with relatively low densities of each plant species (Dixon et al. 1987). Finally, Doyle (1979) has shown that in species with a constant instantaneous mortality rate during dispersal, an initial "exploratory phase" may be adaptive if the abundance of optimal sites is unpredictable.

I consider here the evolution of habitat-acceptance behavior in a time-limited disperser. This behavior is expressed as the probability that a habitat of a particular type is accepted (i.e., that the dispersing organism settles, rather than searching further) once it has been encountered. The model includes the possibility that the probability of acceptance varies during the course of the dispersal phase. In addition, since the total time available is held constant, the expected future time available declines. (This is often more realistic than the frequent assumption of constant mortality in, e.g., nonfeeding dispersers.) These assumptions are similar to those on which Jaenike (1978) based his model, except that in his inequality (1) it is implicitly assumed that if a host plant (i.e., habitat) of a particular type is rejected, no further hosts of this type will be encountered (or, if encountered, they

\footnotetext{
* Present address: Department of Zoology, La Trobe University, Bundoora, Victoria 3083, Australia.
} 
will not be accepted). The decision to reject a habitat, however, should take into account the possibility of encountering and accepting a similar habitat in the future. The present model, therefore, uses dynamic optimization, in which decisions (probabilities of acceptance) are optimized on the assumption that the behavior throughout the remainder of the dispersal period will also be optimal.

The optimal acceptance behavior (sequence) is determined in relation to various features of the habitat available (abundance, suitability) and the dispersers (searching efficiency and the time available). The effects of soft selection and the mode of reproduction are also discussed.

\section{THE OPTIMAL PROBABILITY OF ACCEPTANCE}

Consider an organism searching at random in an environment containing several habitat types. Two of these, HA and HB, are suitable for colonization; these are present at densities $A$ and $B$. The fitnesses of individuals settling in HA and $\mathrm{HB}$ are $w_{\mathrm{A}}$ and $w_{\mathrm{B}}\left(w_{\mathrm{A}}>w_{\mathrm{B}}\right)$. Mean fitness, $w$, is given by

$$
w=w_{\mathrm{A}} P_{\mathrm{A}}(T)+w_{\mathrm{B}} P_{\mathrm{B}}(T),
$$

where $P_{\mathrm{A}}(T)$ and $P_{\mathrm{B}}(T)$ are the probabilities of having settled in HA or HB by the end of the available search time, $T$. The decision, on which selection acts, is expressed as the probability that a habitat will be accepted by individuals that encounter it. Clearly, it is never beneficial to reject the superior habitat, HA; the acceptance probability for habitat HB will be considered below.

The rates (per searching individual) at which HA and HB are encountered are proportional to their abundances, $A$ and $B$, and to the searching rate, $a$. The settling rates are then

$$
S_{\mathrm{A}}=a A \quad \text { and } \quad S_{\mathrm{B}}=a B u(t),
$$

where $u(t)$ is the probability that an individual will accept a habitat of type HB if it encounters it at time $t$ after the start of the search. The probabilities that an organism eventually settles in HA or HB are

$$
P_{\mathrm{A}}(T)=\int_{0}^{T} a A\left[1-P_{\mathrm{A}}(t)-P_{\mathrm{B}}(t)-m(t)\right] d t
$$

and

$$
P_{\mathrm{B}}(T)=\int_{0}^{T} a B\left[1-P_{\mathrm{A}}(t)-P_{\mathrm{B}}(t)-m(t)\right] u(t) d t,
$$

where $P_{\mathrm{A}}(t), P_{\mathrm{B}}(t)$, and $m(t)$ are the individual's probabilities of having settled in $\mathrm{HA}$ or HB or having died by time $t$. Defining $P_{0}(t)$ as $1-P_{\mathrm{A}}(t)-P_{\mathrm{B}}(t)-m(t)$, and substituting equations (3) and (4) into equation (1), yields the mean fitness,

$$
w=a \int_{0}^{T} P_{0}(t)\left[A w_{\mathrm{A}}+B w_{\mathrm{B}} u(t)\right] d t .
$$

The optimal behavior is the function $u(t)$, which maximizes $w$. Provided that the instantaneous mortality, $v$, is less than $a A\left(w_{\mathrm{A}}-w_{\mathrm{B}}\right) / w_{\mathrm{B}}$, the optimal acceptance 
behavior is always to accept habitat $\mathrm{HA}$ and to reject habitat $\mathrm{HB}$ during an initial discrimination phase, but to accept HB (with probability 1) thereafter (see the Appendix).

We can now consider the optimal duration of the discrimination phase; the reasons for considering only the case in which $v$ is less than $a A\left(w_{\mathrm{A}}-w_{\mathrm{B}}\right) / w_{\mathrm{B}}$ will become apparent in the following section.

\section{OPTIMAL DISCRIMINATION PERIOD}

At time $t^{*}$, the end of the discrimination period, the proportion of dispersers settled in habitat HA is

$$
P_{\mathrm{A}}\left(t^{*}\right)=a A\left[1-e^{-(a A+v) t^{*}}\right] /(a A+v) .
$$

Between $t^{*}$ and $T$, both habitats are accepted, and are thus colonized in proportion to their relative abundances. The final proportions of dispersers in each habitat are then

$$
\begin{aligned}
P_{\mathrm{A}}=a A\left[1-e^{-(a A+v) t^{*}}\right] /(a A+v) & \\
& +a A e^{-(a A+v) t^{*}}\left[1-e^{-(a A+a B+v)\left(T-t^{*}\right)}\right] /(a A+a B+v) \\
P_{\mathrm{B}}= & a B e^{-(a A+v) t^{*}}\left[1-e^{-(a A+a B+v)\left(T-t^{*}\right)}\right] /(a A+a B+v) .
\end{aligned}
$$

Substitution into equation (1) gives the mean fitness,

$$
w=a A w_{\mathrm{A}}\left[1-e^{-G t^{*}}\right] / G+a\left(A w_{\mathrm{A}}+B w_{\mathrm{B}}\right) e^{-G t^{*}}\left[1-e^{-H\left(T-t^{*}\right)}\right] / H,
$$

where $G=a A+v$, and $H=a(A+B)+v$. The optimal discrimination phase is that maximizing $w$; it must satisfy $d w / d t^{*}=0$ and $d^{2} w / d t^{* 2}<0$. Differentiating equation (9) twice with respect to $t^{*}$,

$$
\begin{gathered}
d w / d t^{*}=a A w_{\mathrm{A}} e^{-G t^{*}}-a\left(A w_{\mathrm{A}}+B w_{\mathrm{B}}\right)\left(G e^{-G t^{*}}+a B e^{-H T} e^{a B t^{*}}\right) / H \\
=a e^{-G t^{*}}\left[A w_{\mathrm{A}}-\left(A w_{\mathrm{A}}+B w_{\mathrm{B}}\right)\left(G+a B e^{-H\left(T-t^{*}\right)}\right) / H\right] \\
d^{2} w / d t^{* 2}=-G d w / d t^{*}-a^{2} B e^{-G t^{*}}\left(A w_{\mathrm{A}}+B w_{\mathrm{B}}\right) e^{-H\left(T-t^{*}\right)} .
\end{gathered}
$$

If $d w / d t^{*}=0$, then $d^{2} w / d t^{* 2}<0$. The optimal discrimination period is found by setting equation (10) equal to zero and solving for $t^{*}$ :

$$
\hat{t}=T-\frac{1}{a(A+B)+v} \ln \left[\frac{a\left(A w_{\mathrm{A}}+B w_{\mathrm{B}}\right)}{a A\left(w_{\mathrm{A}}-w_{\mathrm{B}}\right)-v w_{\mathrm{B}}}\right] .
$$

Inspection of equation (10) reveals that if $t^{*}<\hat{t}, d w / d t^{*}>0$, and if $t^{*}>\hat{t}, d w / d t^{*}$ $<0$; thus, the solution (eq. 12) represents a unique and globally stable equilibrium. If $v \geq a A\left(w_{\mathrm{A}}-w_{\mathrm{B}}\right) / w_{\mathrm{B}}, \hat{t}$ is undefined, but before $v$ reaches this value, $\hat{t}=0$. The problem of singular control (see the Appendix) thus never arises.

Several predictions follow immediately from equation (12). The optimal discrimination period $(\hat{t})$ increases with increases in the total available time, $T$; the search rate, $a$; the abundance of the preferred habitat, $A$; the abundance of the inferior habitat, $B$; the difference between fitnesses in the two habitats, $w_{\mathrm{A}}-w_{\mathrm{B}}$; and the survival during dispersal (i.e., decreasing $v$ ). Further predictions arise 
from a consideration of the fitness terms, $w_{\mathrm{A}}$ and $w_{\mathrm{B}}$. These concern the effects of density-dependent population regulation and sexual reproduction.

\section{Independent Density Regulation in the Two Habitats (Soft Selection)}

The effect of independent density regulation is to reduce the mean fitness of individuals settling in crowded habitats. The optimal discrimination period now depends on the behavior of the whole population. For illustration, consider habitats in which only a limited total number of offspring can develop. The mean fitness of individuals accepting habitat HA is then

$$
w_{\mathrm{A}}=\sum_{n=1}^{\infty}\left(n p_{n} K_{\mathrm{A}} / n\right) / \sum_{n=1}^{\infty} n p_{n},
$$

where $n$ is the number of individuals settling in a particular habitat of type HA, $K_{\mathrm{A}}$ is the carrying capacity (i.e., the maximum number of offspring surviving in a habitat of type HA), and $p_{n}$ is the probability that a habitat of type HA is colonized by $n$ individuals. If dispersers are distributed at random among habitats HA, equation (13) becomes

$$
w_{\mathrm{A}}=K_{\mathrm{A}}\left(1-e^{-N_{\mathrm{A}}}\right) / N_{\mathrm{A}},
$$

where $N_{\mathrm{A}}=N P_{\mathrm{A}} / A$, the mean number of colonists per habitat of type HA, and $N$ is the total density of dispersing individuals. Similarly,

$$
w_{\mathrm{B}}=K_{\mathrm{B}}\left(1-e^{-N_{\mathrm{B}}}\right) / N_{\mathrm{B}} .
$$

Since $N_{\mathrm{A}}$ and $N_{\mathrm{B}}$ depend on the behavior of all members of the population, an individual's optimal discrimination phase is also a function of the population's mean $t^{*}$ (here denoted by $\bar{t}$ ). The evolutionarily stable strategy (ESS; Maynard Smith 1974) is the population's mean discrimination phase, $\bar{t}$, for which $\hat{t}(\bar{t})=\bar{t}$. (This value is denoted by $t_{\mathrm{eq}}$.) The stability of this equilibrium can be seen as follows. If $\bar{t}<t_{\mathrm{eq}}$, then $N_{\mathrm{A}}$ is lower and $N_{\mathrm{B}}$ higher than would be the case at $t_{\mathrm{eq}}$; thus, $w_{\mathrm{A}}$ is greater and $w_{\mathrm{B}}$ less than their respective values at equilibrium. This means that $d w / d t^{*}$ (at $\bar{t}$ ) is positive (eq. 10); selection thus favors individuals with a discrimination phase longer than the population's mean. Similarly, if $\bar{t}>t_{\mathrm{eq}}$, selection acts to reduce $\bar{t}$ until $\hat{t}(\bar{t})=\bar{t}$.

The (unique, stable) equilibrium can be calculated by substituting equations (13) and (14) into equation (12), and using iteration to solve

$$
t_{\mathrm{eq}}=T-\frac{\ln x}{a(A+B)+v},
$$

in which

$$
x=\frac{a\left[A K_{\mathrm{A}}\left(1-e^{-N_{\mathrm{A}}}\right) / N_{\mathrm{A}}+B K_{\mathrm{B}}\left(1-e^{-N_{\mathrm{B}}}\right) / N_{\mathrm{B}}\right]}{a A\left[K_{\mathrm{A}}\left(1-e^{-N_{\mathrm{A}}}\right) / N_{\mathrm{A}}-K_{\mathrm{B}}\left(1-e^{-N_{\mathrm{B}}}\right) / N_{\mathrm{B}}\right]-v K_{\mathrm{B}}\left(1-e^{-N_{\mathrm{B}}}\right) / N_{\mathrm{B}}},
$$

where $N_{\mathrm{A}}=N P_{\mathrm{A}} / A$ and $N_{\mathrm{B}}=N P_{\mathrm{B}} / B ; P_{\mathrm{A}}$ and $P_{\mathrm{B}}$ are given by equations (7) and (8), in which $t^{*}$ is replaced by $t_{\text {eq }}$. Figure 1 shows several numerical solutions for the optimal discrimination period. Clearly, as the importance of competition (expressed as population density) increases, $t_{\mathrm{eq}}$ declines: inferior habitats should 


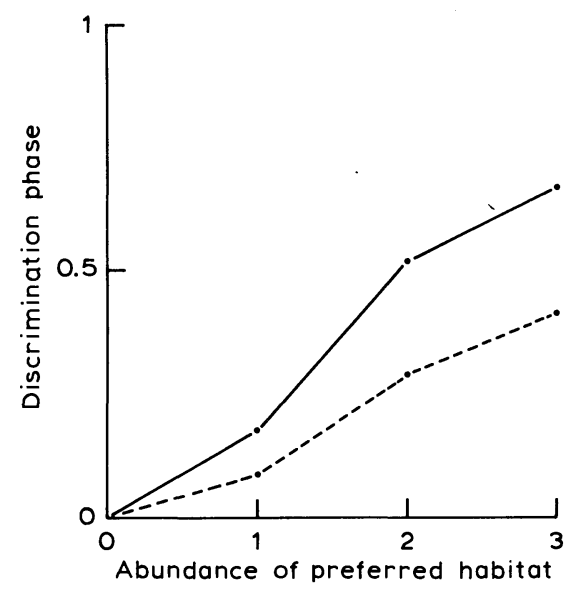

FIG. 1.-The effects of density and the abundance of the preferred habitat on the optimal discrimination phase: solid line, density $(N)=1$; dashed line, $N=10 . K_{\mathrm{A}}=1, K_{\mathrm{B}}=0.5, B$ $=1, a=1, T=1, v=0$.

be accepted more readily as density increases. Qualitatively, this is similar to the prediction of Fretwell and Lucas (1970) that habitat specificity should decline with increasing population density. This model, however, predicts that there are always more animals in habitat HB than would be the case in an ideal free distribution.

\section{Mode of Reproduction}

Here I discuss the effect of sexual reproduction on the optimal discrimination phase, in the absence of independent population regulation. In animals that mate after settling in the habitat (e.g., the sexual generations of aphids), fitness in the habitat is the product of the probability of mating, fecundity, and offspring fitness. For males able to fertilize many females, the term "probability of mating" should be replaced by "expected number of females mated." Grouping fecundity and offspring fitness as one variable ( $L_{\mathrm{A}}$ and $L_{\mathrm{B}}$ in the two habitats), we have the following expressions. (Again, individuals are assumed to be distributed at random among the habitats of a particular type.) For females, which mate only once, the fitnesses of individuals settling in the two habitats are

$$
w_{\mathrm{A}}(f)=L_{\mathrm{A}}\left(1-e^{-M_{\mathrm{A}}}\right) \quad \text { and } \quad w_{\mathrm{B}}(f)=L_{\mathrm{B}}\left(1-e^{-M_{\mathrm{B}}}\right),
$$

where $M_{\mathrm{A}}$ and $M_{\mathrm{B}}$ are the mean numbers of males per habitat $\left(M_{\mathrm{A}}=M P_{\mathrm{A}} / A, M_{\mathrm{B}}\right.$ $=M P_{\mathrm{B}} / B$ ) and $M$ is the total number of male dispersers (for simplicity, it is assumed that if at least one male is present, all females are mated). For males, fitness is inversely proportional to the number of males in a particular habitat. They are thus subject to soft selection of the form expressed in equations (14) and (15), such that

$$
\begin{aligned}
& w_{\mathrm{A}}(m)=L_{\mathrm{A}} F_{\mathrm{A}}\left(1-e^{-M_{\mathrm{A}}}\right) / M_{\mathrm{A}} \\
& w_{\mathrm{B}}(m)=L_{\mathrm{B}} F_{\mathrm{B}}\left(1-e^{-M_{\mathrm{B}}}\right) / M_{\mathrm{B}},
\end{aligned}
$$



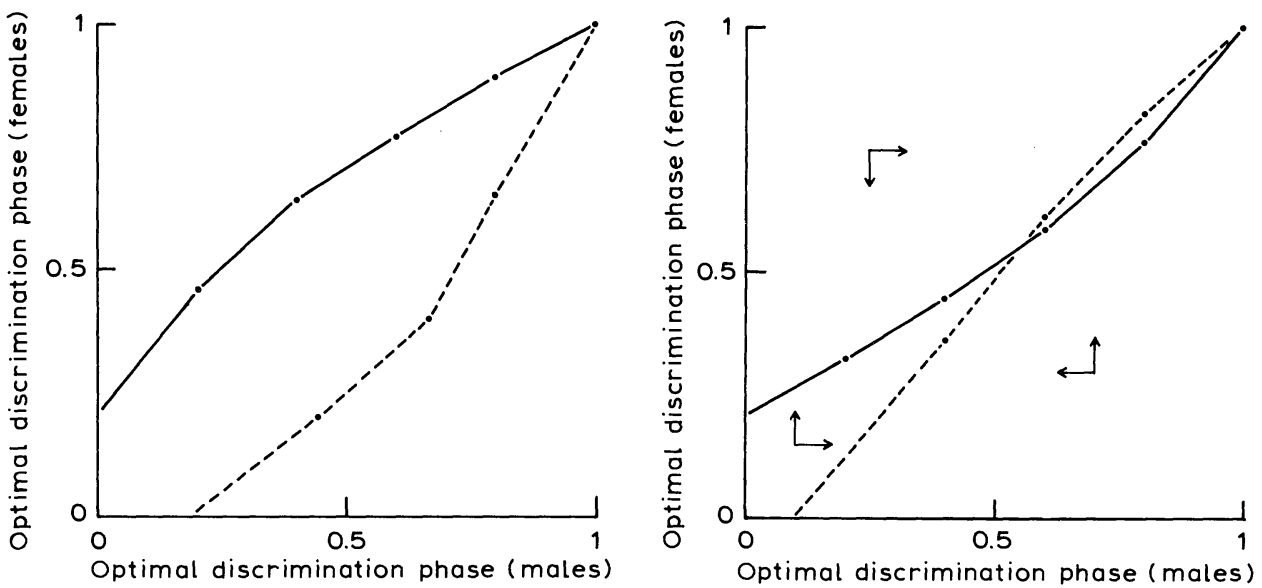

Fig. 2.-Dashed lines, The optimal discrimination phases of males as a function of the discrimination phase of females. Solid lines, Optimal discrimination phases of females as a function of male discrimination. $L_{\mathrm{A}}=1, L_{\mathrm{B}}=0.5, A=1, B=1, a=1, T=1, v=0$. Left, $N=1$. The single evolutionarily stable state is given by the intersection of the optima, $\hat{t}_{\mathrm{m}}=\hat{t}_{\mathrm{f}}$ $=1$. Right, $N=10$. There is now a stable internal optimum at the intersection $\hat{t}_{\mathrm{m}}=\hat{t}_{\mathrm{f}}=0.56$. The arrows show the direction in which populations will be moved by natural selection.

where $F_{\mathrm{A}}$ and $F_{\mathrm{B}}$ are the mean numbers of females per habitat. The optimal discrimination phase for each sex now depends on the behavior of the other.

If males adopt a discrimination phase $t_{\mathrm{m}}$, then $P_{\mathrm{A}}$ and $P_{\mathrm{B}}$ can be calculated by substituting $t_{\mathrm{m}}$ into equations (7) and $(8) ; w_{\mathrm{A}}(f)$ and $w_{\mathrm{B}}(f)$ are then given by equations (17) and can be substituted directly into equation (12) to give $\hat{t}_{\mathrm{f}}$, the optimal discrimination phase for females.

The optimal discrimination phase of males, $\hat{t}_{\mathrm{m}}$, is a function of $t_{\mathrm{f}}$. Substituting $t_{\mathrm{f}}$ into equations (7) and (8) yields $P_{\mathrm{A}}$ and $P_{\mathrm{B}}$ (for females), which then give $F_{\mathrm{A}}=$ $F P_{\mathrm{A}} / A$ and $F_{\mathrm{B}}=F P_{\mathrm{B}} / B$, where $F$ is the total density of female dispersers; $\hat{t}_{\mathrm{m}}$ must be found by iterative solution of

$$
\hat{t}_{\mathrm{m}}=T-\frac{\ln z}{a(A+B)+v},
$$

in which

$$
z=\frac{a\left[A L_{\mathrm{A}} F_{\mathrm{A}}\left(1-e^{-M_{\mathrm{A}}}\right) / M_{\mathrm{A}}+B L_{\mathrm{B}} F_{\mathrm{B}}\left(1-e^{-M_{\mathrm{B}}}\right) / M_{\mathrm{B}}\right]}{a A\left[L_{\mathrm{A}} F_{\mathrm{A}}\left(1-e^{-M_{\mathrm{A}}}\right) / M_{\mathrm{A}}-L_{\mathrm{B}} F_{\mathrm{B}}\left(1-e^{-M_{\mathrm{B}}}\right) / M_{\mathrm{B}}\right]-v L_{\mathrm{B}} F_{\mathrm{B}}\left(1-e^{-M_{\mathrm{B}}}\right) / M_{\mathrm{B}}},
$$

since $M_{\mathrm{A}}$ and $M_{\mathrm{B}}$ are functions of $\hat{t}_{\mathrm{m}}$.

There are four main features of the numerical example presented in figure 2. (1) Since the values of matings in the two habitats differ, members of one sex should discriminate $(\hat{t}>0)$ even if the other sex does not. (2) If one sex never accepts habitat HB $\left(t_{\mathrm{m}}\right.$ or $\left.t_{\mathrm{f}}=T\right)$, neither should the other. (3) As the density of males increases, the optimal discrimination period for females declines toward that of an unregulated parthenogenetic species. (4) At the same time (i.e., with increasing 
density of males), the optimal discrimination period for males falls toward that for a parthenogenetic population under density-dependent regulation, as calculated using equations (14) and (15).

With selection acting on both sexes, the population will move toward the ESS defined by the intersection of the curves for males and females, unless the starting point is the failure to recognize habitat $\mathrm{HB}\left(t_{\mathrm{m}}=t_{\mathrm{f}}=T\right)$. This equilibrium, however, is unstable, because if $t^{*}=T$,

$$
d w / d t^{*}=-a B w_{\mathrm{B}} e^{-(a A+v) T}<0
$$

(from eq. 10). Thus, although $w_{\mathrm{B}}(m)=w_{\mathrm{B}}(f)=0$ if $t_{\mathrm{f}}=t_{\mathrm{m}}=T$, any perturbation from this equilibrium results in selection for a reduction in $t_{\mathrm{f}}$ and $t_{\mathrm{m}}$.

Returning to the internal ESS, it is shown below that, at equilibrium, males and females are equally discriminating. Equation (10) is equivalent to $d w / d t^{*}=$ $w_{\mathrm{A}}\left(d P_{\mathrm{A}} / d t^{*}\right)+w_{\mathrm{B}}\left(d P_{\mathrm{B}} / d t^{*}\right)$, such that for males,

$\frac{d w_{\mathrm{m}}}{d t_{\mathrm{m}}}=L_{\mathrm{A}}\left(1-e^{-M_{\mathrm{A}}}\right)\left(F_{\mathrm{A}} / M_{\mathrm{A}}\right) \frac{d P_{\mathrm{A}}(m)}{d t_{\mathrm{m}}}+L_{\mathrm{B}}\left(1-e^{-M_{\mathrm{B}}}\right)\left(F_{\mathrm{B}} / M_{\mathrm{B}}\right) \frac{d P_{\mathrm{A}}(m)}{d t_{\mathrm{m}}}$,

and for females,

$$
\frac{d w_{\mathrm{f}}}{d t_{\mathrm{f}}}=L_{\mathrm{A}}\left(1-e^{-M_{\mathrm{A}}}\right) \frac{d P_{\mathrm{A}}(f)}{d t_{\mathrm{f}}}+L_{\mathrm{B}}\left(1-e^{-M_{\mathrm{B}}}\right) \frac{d P_{\mathrm{B}}(f)}{d t_{\mathrm{f}}} .
$$

If $t_{\mathrm{m}}=t_{\mathrm{f}}$, then $F_{\mathrm{A}} / M_{\mathrm{A}}=F_{\mathrm{B}} / M_{\mathrm{B}}=F / M, d P_{\mathrm{A}}(f) / d t_{\mathrm{f}}=d P_{\mathrm{A}}(m) / d t_{\mathrm{m}}$, and $d P_{\mathrm{B}}(m) / d t_{\mathrm{m}}$ $=d P_{\mathrm{B}}(f) / d t_{\mathrm{f}}$, such that

$$
d w_{\mathrm{f}} / d t_{\mathrm{f}}=(F / M)\left(d w_{\mathrm{m}} / d t_{\mathrm{m}}\right) .
$$

Thus, if $t_{\mathrm{m}}=t_{\mathrm{f}}$, selection favors similar changes in the discrimination phases of both males and females; that is, the discrimination phases of the two sexes should both increase or both decline, unless $d w_{\mathrm{f}} / d t_{\mathrm{f}}=d w_{\mathrm{m}} / d t_{\mathrm{m}}=0$. The curves $\hat{t}_{\mathrm{f}}\left(t_{\mathrm{m}}\right)$ and $\hat{t}_{\mathrm{m}}\left(t_{\mathrm{f}}\right)$ can, therefore, never lie on the same side of the line $t_{\mathrm{m}}=t_{\mathrm{f}}$ (see fig. 2), and any equilibrium must lie on this line of equality.

It is now possible to determine the optimal discrimination phase for animals that mate after settling in the habitat, with both sexes adopting the same discrimination phase. The mean fitnesses of individuals settling in the two habitats are now given by the weighted means of the fitnesses of males and females:

$$
\begin{aligned}
w_{\mathrm{A}} & =\left[M_{\mathrm{A}} w_{\mathrm{A}}(m)+F_{\mathrm{A}} w_{\mathrm{A}}(f)\right] /\left(M_{\mathrm{A}}+F_{\mathrm{A}}\right) \\
& =L_{\mathrm{A}}\left(1-e^{-M_{\mathrm{A}}}\right)\left(M_{\mathrm{A}} F_{\mathrm{A}} / M_{\mathrm{A}}+F_{\mathrm{A}}\right) /\left(M_{\mathrm{A}}+F_{\mathrm{A}}\right) \\
& =2 L_{\mathrm{A}}\left(1-e^{-M_{\mathrm{A}}}\right) F / N ;
\end{aligned}
$$

and

$$
w_{\mathrm{B}}=2 L_{\mathrm{B}}\left(1-e^{-M_{\mathrm{B}}}\right) F / N .
$$

$F / N$ replaces $F_{\mathrm{A}} / N_{\mathrm{A}}$ and $F_{\mathrm{B}} / N_{\mathrm{B}}$, because with $t_{\mathrm{m}}=t_{\mathrm{f}}$ the sex ratios in the two habitats are equal. The optimal discrimination phase can be calculated by iteration, after substituting equations (24) into equation (12). As shown in figure 3, unless the population density is high (in this example, approaching 100 dispersers 


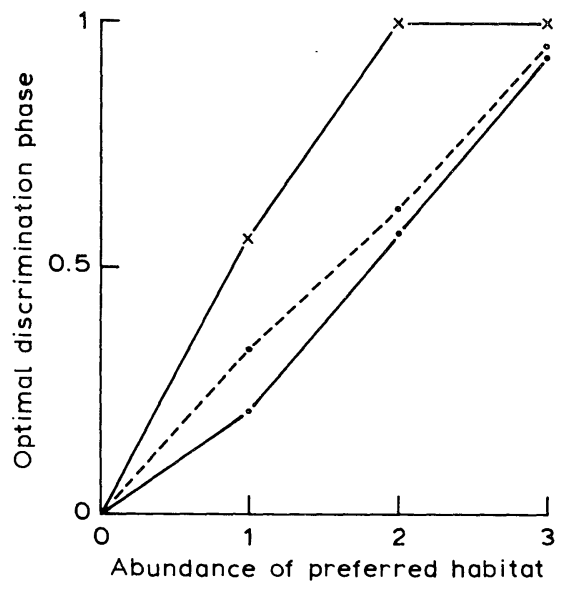

FIG. 3.-The optimal discrimination phase for dispersers that mate after settling, in relation to the abundance of the preferred habitat. $L_{\mathrm{A}}=1, L_{\mathrm{B}}=0.5, T=1, v=0$. Solid line with $\mathrm{x}$ 's, $N=10, \mathrm{~B}=1 ;$ solid line with dots, $N=100, B=1$; dashed line, $N=100, B=2$.

per habitat), $\hat{t}$ is very close to $T$ : suboptimal habitats should be accepted only by dispersers at the point of death.

\section{DISCUSSION}

The evolution of strategies for habitat selection is thought to depend mainly on the suitabilities and availabilities of the various habitat types. Thus, individuals should colonize poor habitats (or hosts) only if their chance of finding a better habitat is low. Several models have been developed in which this chance is limited not only by the abundance of superior habitats but also by constraints on the time available for dispersal (Levins and MacArthur 1969; Jaenike 1978; Courtney 1982) or by mortality during the search period (Doyle 1979). Most of these models, however, concern the existence of absolute preference: that is, dispersers should either always or never accept inferior habitats. The predictions of these models are not easily related to data on partial preference. Jaenike (1978) did provide a useful framework for understanding partial preference, but his optimization of a decision at one stage in the dispersal period fails to allow for the effects of future changes in behavior.

My model differs from that of Jaenike in two main respects. First, it does not require that the probability of acceptance is either 0 or 1 ; that is, it permits the existence of intermediate acceptance probabilities. For example, a clone of aphids might contain a mixture of specialist and generalist individuals, or (the formal equivalent) each individual might have a constant tendency to settle on an inferior host, irrespective of the time already spent searching. Second, dynamic optimization is used to determine the optimal behavioral sequence; the optimal probability of accepting a habitat at a given time thus depends on the probability that a similar habitat will be encountered and accepted later on during the dispersal period. 
The model's five main predictions are listed below.

1. The optimal acceptance behavior involves "bang-bang" control. There should be an initial "discrimination phase," during which inferior habitats should never be accepted; after this period, both superior and inferior habitats should be accepted whenever they are encountered (Jaenike 1978). As Singer (1982) has pointed out, such a discrimination phase provides an excellent quantitative index of habitat specificity; it is directly measurable, and avoids the difficulties associated with inferring behavioral characteristics from data about habitat utilization by populations.

2. The duration of the optimal discrimination phase increases with (a) the searching efficiency and the time available for searching; (b) the abundance of optimal habitats; (c) the abundance of inferior habitats; (d) the difference between the suitabilities of the two habitats; and (e) the survival during the dispersal period. Predictions $a, b, d$, and e are qualitatively similar to the predictions of Levins and MacArthur (1969), Doyle (1979), and Courtney (1982), but they now concern not merely the exclusion of inferior habitats (or hosts) from the optimal range, but the strength of the preference for one habitat over another. Predictions $\mathrm{a}, \mathrm{b}$, and $\mathrm{d}$ have also been derived by Jaenike, but his model predicts also that "the abundance of a given plant does not affect the time at which it should be accepted" (1978, p. 352). The model presented here, however, predicts that the more abundant a (suboptimal) habitat is, the less readily it should be accepted; as inferior habitats become more abundant, the dispersing individuals can afford to wait longer before accepting them. This model differs because it uses dynamic optimization in which the optimal probability of acceptance at a given time is related to the sequence of behavior during the rest of the dispersal period. Further predictions can be derived by considering the factors determining the relative suitabilities of different habitats.

3. Density-dependent regulation of populations within habitats reduces the optimal discrimination phase; that is, "soft selection" (Wallace 1968) should prevent extreme habitat specificity. Qualitatively, this prediction is similar to those of Fretwell and Lucas (1970). Their "ideal free distribution" is not attained, however, because of the direct relation between preference and fitness (Rausher 1984), which, in this case, is caused by the constraint on the dispersal period.

4. Another important factor is the failure to mate. In species that mate after settling in a habitat, mating success depends on habitat choice. The model predicts that males (which are assumed to be able to mate many times) and females (which mate only once) should be equally specific in their choice of habitats.

5. Finally, the optimal discrimination phase of species that mate after settling in the habitat is much greater than that of parthenogenetic organisms or of those mating before the dispersal phase, unless the population density (per habitat) is large. The magnitude of this effect (see fig. 3) suggests that varying success in finding mates is a major selective pressure for host specificity and site specificity in parasites, as concluded by Rohde (1979). Further support for this idea may come from Eastop (1973), who found from his survey of host range in aphids (Ward 1987, in prep.) that the range of secondary summer hosts (which has no effect on mating success) is generally greater in species that alternate hosts than in species with a more constant host range throughout the year (whose chance of 
mating thus depends on host choice). In addition, species that alternate hosts generally show extreme specificity in their choice of winter hosts, on which mating occurs.

In conclusion, the above model incorporates a number of important biological constraints, but it also includes the possibility of changes in the tendency of dispersing individuals to accept inferior habitats. It yields a wide range of predictions concerning both the nature of the mechanism of habitat selection (i.e., the discrimination phase) and the effects of ecological and biological factors on the strength of the preference for the optimal habitat.

\section{SUMMARY}

A model is constructed and then used to examine the optimal settling (or habitat- or host-acceptance) behavior of organisms with only a limited amount of time available for dispersal, in an environment containing two types of habitat (or host). The model's predictions follow.

The dispersal period should be characterized by a discrimination phase or, if many different habitats are available, a series of discrimination phases. During this phase, the more-suitable habitat is accepted whenever it is encountered, and the less suitable is always rejected; afterward, both habitats should always be accepted. Such discrimination phases may provide a useful measure of the habitat preferences of individuals (Singer 1982).

The duration of the discrimination phase (i.e., the degree of habitat specificity) should increase with searching efficiency, the time available, the abundance of both habitat types, the difference between the fitnesses of organisms settling in the two habitat types, and survival during dispersal. Density-dependent population regulation acting independently in the two habitats reduces the degree of habitat specificity.

If mating occurs after settling, males and females should be equally and strongly habitat-specific. This prediction lends support to Rohde's (1979) conclusion that failure to find mates is an important factor limiting the host and site ranges of parasites.

\section{ACKNOWLEDGMENTS}

This work has benefited greatly from thorough and constructive criticism by A. Dixon, R. Rabbinge, D. Thiery, M. Rausher, and two anonymous referees. I am grateful also to B. van Amersfoort for typing the manuscript and to the International Agricultural Centre (Wageningen) and the Agricultural University of Wageningen for financial support.

\section{APPENDIX}

\section{Optimal Control}

Using Pontryagin's maximum principle (Kopp 1962; Leitman 1966; for biological applications, see León 1976; Schaffer 1983), the problem of maximizing the integral (eq. 5) is 
equivalent to maximizing the Hamiltonian:

$$
\mathscr{H}=P_{0}\left[A w_{\mathrm{A}}+B w_{\mathrm{B}} u(t)\right]+Y d P_{0} / d t,
$$

where the adjoint variable, $Y$, is a time-dependent analogue of the Lagrange multipliers used in static optimization (Vincent and Pulliam 1980). It is defined by

$$
\begin{aligned}
d Y / d t & =-\partial \mathscr{H} / \partial P_{0} \\
& =A\left(a Y-w_{\mathrm{A}}\right)+B\left(a Y-w_{\mathrm{B}}\right) u(t)+v Y, \quad Y(T)=0,
\end{aligned}
$$

where $v$ is the instantaneous relative mortality during dispersal. Since $d P_{0} / d t=-\left(S_{\mathrm{A}}+S_{\mathrm{B}}\right.$ $+v) P_{0}$, equation (A1) becomes

$$
\mathscr{H}=P_{0}\left[A w_{\mathrm{A}}+B w_{\mathrm{B}} u(t)\right]-[a A+a B u(t)+v] Y P_{0} .
$$

Taking the first partial derivative of $\mathscr{H}$ with respect to $u(t)$ :

$$
\partial \mathscr{H} / \partial u(t)=P_{0} B\left(w_{\mathrm{B}}-a Y\right) \text {. }
$$

With $P_{0} B$ positive, the optimal probability of acceptance depends on the switching function,

$$
c=w_{\mathrm{B}}-a Y .
$$

If $c>0$, the optimal acceptance probability, $u(t)$, equals 1 ; if $c<0$, then $\hat{u}(t)=0$ and, for 0 $<\hat{u}(t)<1, c$ must equal zero for a finite time. To find whether the optimal control can be "singular" (i.e., $0<\hat{u}[t]<1$ ), consider

$$
\begin{aligned}
d c / d t & =-a d Y / d t \\
& =a\left[A\left(w_{\mathrm{A}}-a Y\right)+B\left(w_{\mathrm{B}}-a Y\right) u(t)-v Y\right] \\
& =a\left[A\left(c+w_{\mathrm{A}}-w_{\mathrm{B}}\right)+B c u(t)-v\left(w_{\mathrm{B}}-c\right) / a\right] .
\end{aligned}
$$

Singular control in $u$ requires that $c=d c / d t=0$. With $c=0$, however,

$$
d c / d t=a A\left(w_{\mathrm{A}}-w_{\mathrm{B}}\right)-v w_{\mathrm{B}},
$$

which is positive provided that $v<a A\left(w_{\mathrm{A}}-w_{\mathrm{B}}\right) / w_{\mathrm{B}}$.

Thus, unless $v \geq a A\left(w_{\mathrm{A}}-w_{\mathrm{B}}\right) / w_{\mathrm{B}}$, the optimal behavior sequence involves an initial "discrimination phase," in which $\hat{u}(t)=0$ (habitat HB is never accepted); during the rest of the dispersal period, $\hat{u}(t)=1$ (habitat $\mathrm{HB}$ is accepted whenever encountered).

\section{LITERATURE CITED}

Courtney, S. P. 1982. Coevolution of pierid butterflies and their cruciferous food-plants. V. Habitat selection, community structure and speciation. Oecologia (Berl.) 54:101-107.

Dixon, A. F. G., P. Kindlmann, J. Lepš, and J. Holman. 1987. Why there are so few species of aphids, especially in the tropics. Am. Nat. 129:580-592.

Doyle, R. W. 1979. Settlement of planktonic larvae: a theory of habitat selection in varying environments. Am. Nat. 109:113-126.

Eastop, V. F. 1973. Deductions from the present-day host plants of aphids and related insects. Pages 157-178 in H. F. van Emden, ed. Insect/plant relationships. Blackwell, Oxford.

Fretwell, S. D. 1972. Populations in a seasonal environment. Princeton University Press, Princeton, N.J.

Fretwell, S. D., and H. L. Lucas. 1970. On territorial behaviour and other factors influencing habitat distribution in birds. Acta Biotheor. 19:16-36.

Jaenike, J. 1978. On optimal oviposition behavior in phytophagous insects. Theor. Popul. Biol. 14:350-356.

Kopp, K. E. 1962. Pontryagin maximum principle. Pages $255-280$ in G. Leitmann, ed. Optimization techniques: with applications to aerospace systems. Academic Press, New York.

Leitmann, G. 1966. An introduction to optimal control. McGraw-Hill, New York. 
León, J. A. 1976. Life histories as adaptive strategies. J. Theor. Biol. 60:301-336.

Levins, R. 1968. Evolution in changing environments. Princeton University Press, Princeton, N.J.

Levins, R., and R. H. MacArthur. 1969. An hypothesis to explain the incidence of monophagy. Ecology 50:910-911.

Maynard Smith, J. 1974. The theory of games and the evolution of animal conflicts. J. Theor. Biol. 47:209-221.

Rausher, M. D. 1984. The evolution of habitat preferences in subdivided populations. Evolution 38:596-608.

Rohde, K. 1979. A critical evaluation of intrinsic factors responsible for niche restriction in parasites. Am. Nat. 114:648-671.

Schaffer, W. M. 1983. The application of optimal control theory to the general life history problem. Am. Nat. 121:418-431.

Singer, M. C. 1982. Quantification of host preference by manipulation of oviposition behavior in the butterfly Euphydryas editha. Oecologia (Berl.) 52:224-229.

Vincent, T. L., and H. R. Pulliam. 1980. Evolution of life history strategies for an asexual annual plant model. Theor. Popul. Biol. 17:215-231.

Wallace, B. 1968. Polymorphism, population size, and genetic load. Pages 87-108 in R. C. Lewontin, ed. Population biology and evolution. Syracuse University Press, Syracuse, N.Y.

Ward, S. A. 1987. Cyclical parthenogenesis and the evolution of host range in aphids. In J. Holman and A. F. G. Dixon, eds. Population structure, genetics and taxonomy of aphids. Academia, Prague (in press). 